\title{
Interactive comment on "Importance of radiative transfer processes in urban climate models: A study based on the PALM model system 6.0" by Mohamed H. Salim et al.
}

\section{Anonymous Referee \#1}

Received and published: 17 February 2021

In this manuscript, the author use the newest PALM model at a spatial resolution of 1 meter to simulate various radiative transfer processes within two urban canyon (ideal and real) environments. First of all, it is very well written in a comprehensive way and considers also other meteorological properties such as the variational air flow due to the changed radiation inside urban canyons. However, the usage of a not validated simulation as a reference (in this case RTM_08) is not appropriate. Here, the authors should consider an alternative word or provide similar simulations with other models for comparing (see major comment 1). 
1) Page 9, line 27: The simulation RTM_08 can not be a reference, mainly due to (i) the PALM model is not yet validated in a sufficient extent and (ii) as shown in Resler et al. (2020), the land surface temperature under tree shades is underestimated. Hence, the LW radiation could be wrong in the RTM_08 simulation.

2) Page 3, line 10: The authors mentoined that the manuscript does not engage with validating the RTM. This should be also mentoined in the conclusions as it is only a split-up of different processes without any comparisons to other models/observations.

3) Page 7, line 27: New studies showed that the assumption of emissivity is not true https://doi.org/10.1016/j.scienta.2012.01.022 . Otherwise use a reference for this value.

4) Page 8, line 9: Could you please specify in the text, what is ment by "only ONE SINGLE reflection"? Is it referred to one single reflection of the whole area or to the iteration?

5) Page 8, line 19: What is the reason behind this (four iterative reflection)? Please justify your decision or include a reference that shows the decreased importance of higher ordered multiple reflections.

6) Page 8, line 27: Section 3.1, please give additional information regarding the pavement characteristics in this configuration. In the results (4.1.2), the effect of pavement is highlighted, however it is not clear, if all surfaces between the buildings (incl. under the trees) are paved or not.

7) Page 9, line 28-29: Simmilarly to the "simple urban configuration" (major comment $6)$, do the results of the "realistic urban geometry" case refer to a defined focus domain or to the whole area $(1 \times 1 \mathrm{~km} 2)$ ?

Printer-friendly version

8) Page 11, line 15-16: How would the authors explain the results for 3b RTM_04?

9) Page 15, line 24: The effect of vegetation is in accordance with the vegetated area based on the satellite image, however based on Fig. 2. it seems that only a limited

Discussion paper

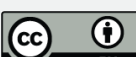


amount of plant canopy boxes were considered in the simulations. Did the authors make additional assumptions regarding vegetated areas in the realistic urban configuration?

10) Page 17, line 25: In Fig. 26, how would the authors explain the results of $26 \mathrm{c}$ (potential temperature) in case of RTM_01?

11) Page 20, line 1: The authors point out that their aim was to evaluate the performance of PALM/PALM-4U simulations using different radiation transfer processes. In the first funding phase of MOSAIK, a measurement campaing was completed in order to evaluate the model results based on measurements. I would suggest to refer to these ongoing activities in Section 4.5.

12) Page 20, line 20-23: The statements have to be seen in relative terms as RTM_08 was considered as a reference for the comparison in the study. If possible, cite other studies with similar RTM methods and compare them.

Minor comments

Page 1, line 6: Typo - twice "the"

Page 2, line 2: Insert some citations

Page 3, line 19: Please highlight that there are ongoing PALM-4U urban-related developments (e.g. physical implementations, evaluating the interaction of different modules and the practicability) in the framework of the second funding phase of MOSAIK.

Page 3, line 26: Abbrivation SGS necessary if only used once?

Page 6, line 1: Captions (here Table 1) should be written as a stand-alone text. So please describe all abbrivations.

Printer-friendly version

Discussion paper within a surface.

Page 6, line 11: Do you mean "each grid cell" instead of "each surface"? It variates 
Page 8, line 17: See major comment 3 with emissivity of leafs.

Page 11, line 13: Fig. 3a, please use a dashed line as last to see other colors immedatily OR give a note in the caption of the figure.

Page 12, line 16: Please consider the comment above regarding pavement surfaces (major comment 6).

Page 13, line 9: Typo - it is Fig. 9a.

Page 14, line 14-15: Descriptions should be in section 2, not in results.

Page 14, line 21: Typo - Fig. 3b

Page 17, line 31-32: Please highlight, that the results were compared to RTM_08.

Page 20, line 5: The PALM/PALM-4U model system is under development, new revisions are made available very frequently. In order to follow further developments, I would suggest the authors to include the revision number of the model version used in this study.

Page 28, Fig 1: An additional north narrow would make the orientation in the focus domain easier.

Page 29, Fig 2: If you use Google maps pictures, the Google copyright sign needs to be inside the picture too!

Page 31, Fig 4: Typo - blue is referred to LW.

Page 33, Fig 6: Unit is missing. See also other similar plots with buildings (Figs. 8, 10, $12,14,16,18)$.

Page 33, Fig 6: Rectangles in the corners are the roofs, isn't it?

Printer-friendly version

Page 38, Fig 11: Typo - LW in Fig. 11b.

Discussion paper

Page 50, Fig 23: Please make sure that $0 \mathrm{~W} / \mathrm{m} 2$ is white and not gray. Maybe you can 
mask buildings to see urban canyons better. See also Google maps comment!

Please also note the supplement to this comment:

https://gmd.copernicus.org/preprints/gmd-2020-94/gmd-2020-94-RC1-supplement.pdf

Interactive comment on Geosci. Model Dev. Discuss., https://doi.org/10.5194/gmd-2020-94, 2020. 